\title{
OIL SPILL TRAJECTORY: A COMPARISON BETWEEN 2D AND 3D MODELS
}

\author{
ABDELLATIF SOUSSI ${ }^{1}$, CHIARA BERSANI $^{1,2}$ \& ANGELA MARIA TOMASONI ${ }^{2}$ \\ ${ }^{1}$ Italian Centre of Excellence on Logistics, Transport and Infrastructures (CIELI), University of Genova, Italy \\ ${ }^{2}$ Department of Informatics, Bioengineering, Robotics and Systems Engineering, University of Genova, Italy
}

\begin{abstract}
Oil spills in the marine environment are a harmful threat to the environment, the population, and the economy. For this reason, it is important to know the trajectory of oil slicks in case of a spill in order to prioritize actions for oil recovery and thus to better protect areas exposed to pollution risk. For this purpose, several oil slick drift models are developed to study the impact of various possible scenarios and to estimate the environmental sensitivity of a maritime and coastal area even before this type of accident occurs. In this context, this paper presents the applications of a two (2D) and three-dimensional (3D) oil spill models, suggested to define the trajectory of the oil slick in a marine environment taking into account different meteorological parameters. The two models have been applied to simulate the oil spill propagation in the case of a collision accident that occurred off Saint-Tropez (France) on 7 October 2018.
\end{abstract}

Keywords: oil spill, trajectory modelling, GNOME model, environmental impact.

\section{INTRODUCTION}

Oil spills on the marine environment represent serious threats both for valuable biodiversity and for the marine environment that has to be protected and preserved [1]-[3]. The impact of the consequences also generates immediate economic losses and negative effects on the population living in the vicinity of the contaminated environment. Also damages related to accidents which involve dangerous good storage [4] and transportation by road [5], [6] or by rail [7] affect seriously the neighbour area, but oil spills may have long-term adverse effects on ecosystems where they cause degradation of marine flora and fauna [8]-[10]. These effects depend on several variables, such as the location and meteorological conditions at the time of the spill, wind and sea current, as well as the quantity, spill rate, and type of oil [11], [12]. Due to the severity of the impacts that an oil spill can have in the aquatic environment, it is important to be able to identify the trajectory of oil slicks in order to prioritize actions for oil recovery in the event of a spill and thus to better protect the areas exposed to the risk of pollution [13]. The development of oil slick drift models in the marine environment is motivated by the frequency of pollution and the adverse effects of such pollution on the environment [14]. These models allow to study the impact of various possible scenarios and thus estimate the environmental sensitivity of a marine and coastal area before such accidents occur [15]-[19]. The purpose and capability of oil slick drift models range from simple trajectory tracking to two dimensional or three-dimensional (2D or 3D) transport models, able to predict oil distributions at the surface, in the water column [20], taking into consideration the various behavioural characteristics of oil during the weathering process [21]. The most complex models can also quantify biological responses and environmental impacts [22]. In recent decades, several models have been developed and applied in different studies to simulate the movements of the spilled oil with the purpose to develop pollution response and emergency plans [23]. These include the oil spill trajectory models used by the NOAA OR\&R Emergency Response Division GNOME (General NOAA Operational Modeling Environment) [24], [25] and ADIOS (Automated Data Inquiry for Oil Spills) [26], the Oil Spill Model System (OILMAP) [27]-[29], OSCAR (Oil Spill Contingency and. 
Response Model) [30], [31], the MOHID Oil Spill Model operational system [32], OilTrans [33] and the Medslik-II model [34].

The majority of existing spill models are based on a random walk strategy to model the movement of the spill on the surface and water column [35]-[37]. These latter models use Lagrangian methods to predict the transport processes (advection and dispersion), assuming that the spilled product consists of a large number of particles that move through the water according to dispersion patterns [38], [39]. The Lagrangian particle movements are conditioned by wind direction and speed, waves, and currents [40]. The models based on the three-dimensional processes (3D) [41], [42] consist of a set of algorithms to perform a simulation of the fate and transport of the oil slick on the surface and the water column, also considering the process of diffusion, vertical mechanical dispersion, evaporation, emulsification and stranding [43]. On the other hand, generally, the two-dimensional (2D) models focused only on the surface transport processes [22].

In this context, this paper presents two applications suggested to identify areas at risk that could be affected in case of a spill. The first presented approach is a 2D Lagrangian model, and the second is a 3D model GNOME (General NOAA Operational Modelling Environment) developed by NOAA's. The simulations have been tested on the real case of the collision occurring on 7 October 2018, at the coast of Saint-Tropez (France).

\section{MODEL DEFINITION}

\subsection{The 2D model proposed}

When released into the sea, hydrocarbons undergo a variety of transformation processes such as drifting and spreading, evaporation, dissolution, dispersion, emulsification, photooxidation, biodegradation, and sedimentation [44]. These processes are greatly influenced by hydrocarbon composition and environmental characteristics [45]. The proposed 2D model [46] defines the processes of propagation, advection, and diffusion that draw the trajectory of the oil slick in the event of a spill. This model is based on the Lagrangian approach which considers the oil slick in the water as the movements of a set of particles driven by wind, waves, and currents, and which may float up or down by buoyancy [47], [48]. In terms of convection, many $2 \mathrm{D}$ oil slick drift models use a constant parameter to relate surface wind speed to slick drift. The Lagrangian particle motions are conditioned in direction and velocity by the vector sum of $3.5 \%$ of the wind speed [49]. Tidal and permanent currents can usually be included based on different databases [50]-[52]. In the Lagrangian approach, the particles of the slick, on the surface or in suspension, will have a random motion in addition to the regular motion due to the main current to represent the turbulent diffusion. The stochastic speed is then adjusted from the time scale and the diffusion coefficient. In this model, the motion of the oil slick, at the water surface level, may be considered to be composed of the advection of the oil slick, through surface currents, wind effects, and oil particle diffusion, resulting from random processes. Most particle-based oil slick drift algorithms (Lagrangian) are based on the theory of Fay [53]. In this approach, it is assumed that the slick extension increases in the wind direction with time in proportion to the wind speed, while the lateral elongation is always written by the gravity spreading equation described in [53], [54]. Indeed, in the proposed model based on the diffusion equation [46], the movement of an oil slick on the surface of the water is the result of two main physical phenomena: on the one hand, the horizontal spreading of oil slicks under the effect of mechanical forces, such as gravity, inertia, viscosity and interfacial tension, and on the other hand, turbulent diffusion [45]. Within the next phase of viscous gravity spreading, the oil slick spreading can have an 
elliptical shape on the water surface with the major axis oriented in the wind direction (Fig. 1).

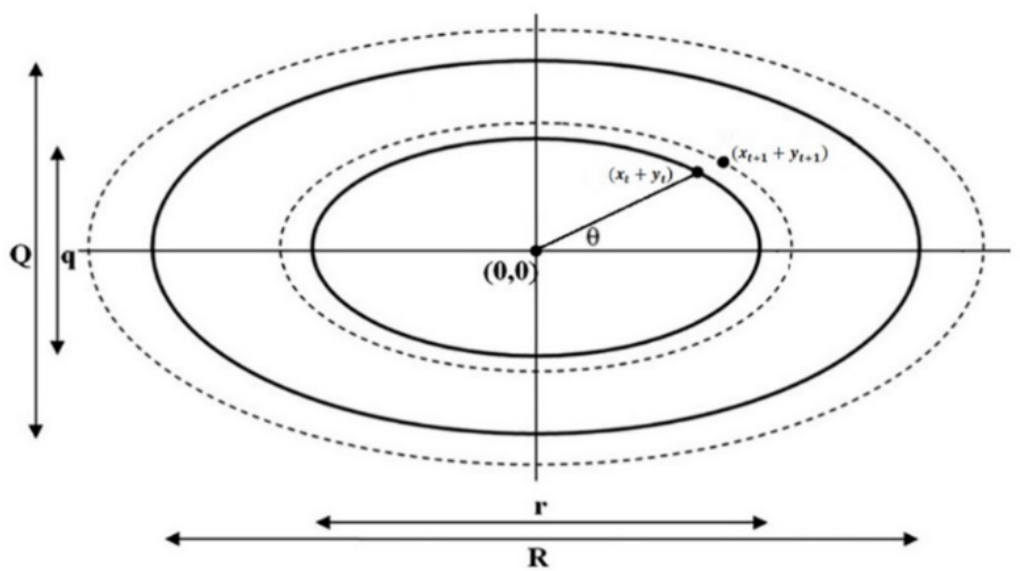

Figure 1: Elliptical spreading of a surface slick.

The area $A_{t}$ covered by the oil slick $\left(\mathrm{m}^{2}\right)$ from the time $t_{0}$, is given by:

$$
A_{t}=\frac{1}{4} \pi Q_{t} R_{t}
$$

where $Q_{t}$ is the length of the minor ellipse axis $(\mathrm{m})$ :

$$
Q_{t}=1.7\left(\Delta \rho V_{0}\right)^{1 / 3} t^{1 / 4}
$$

And $R_{t}$ is the length of the major axis of the oil slick ellipse $(\mathrm{m})$ :

$$
R_{t}=Q_{t}+0.03 *\left(U_{\text {wind }}\right)^{4 / 3}(t)^{3 / 4},
$$

where $\mathrm{V}_{0}$ is the volume of oil spill in barrels, $\Delta \mathrm{i}$ is the relative density difference between the water and oil, the time $t$ is time in minutes, and $U_{\text {wind }}$ is the wind speed in Knots, and $\mathrm{t}$ is time in minutes. [55]:

The displacement of the oil slick due to advection and horizontal diffusion is given by

$$
\begin{aligned}
& X_{t+1}=x_{t}+u_{a, x} \Delta t+\Delta x_{d i f f}, \\
& Y_{t+1}=y_{t}+u_{a, y} \Delta t+\Delta y_{d i f f},
\end{aligned}
$$

where:

- $x_{t}, y_{t}$ is the location of the particles at time step t-th;

- $u_{a, x}$ and $u_{a, y}$ are the advective velocities in the $X$ and $Y$ directions respectively;

$$
U_{a(x, y)}=U_{\text {current }}+0.035 U_{\text {wind }}
$$

- $\Delta t$ is the time-step interval (s);

- $\Delta X_{\text {diff }}, \Delta Y_{\text {diff }}$ are the translations of the particles in the $\mathrm{X}$ and $\mathrm{Y}$ directions respectively. 


$$
\begin{aligned}
& \Delta x_{\text {diff }}=[R]_{0}^{1} \sqrt{12 D_{h} \Delta t} \cos \theta, \\
& \Delta y_{\text {diff }}=[R]_{0}^{1} \sqrt{12 D_{h} \Delta t} \sin \theta,
\end{aligned}
$$

where:

- $\quad[\mathrm{R}]_{0}^{1}$ is a random number between 0 and 1 from a uniform distribution;

- $D_{h}$ : horizontal diffusion coefficient $\left(\mathrm{m}^{2} / \mathrm{s}\right)$;

- $\quad$ and $\theta$ is the directional angle $\theta=2 \pi\left[\mathrm{R}^{\prime}\right]_{0}^{1}$. (where $\left[\mathrm{R}^{\prime}\right]_{0}^{1}$ is a random number between 0 and 1 .

\subsection{The GNOME model}

The General NOAA Operational Modelling Environment, called GNOME, (https://gnome.orr.noaa.gov/\#) is an oil spill trajectory model developed by the NOAA Office of Response and Restoration's Emergency Response Division [56]. This approach is based on a discrete Lagrangian element that allows to simulate the behaviour of the oil spill during the weathering process which includes spreading, evaporation, dispersion, and advection [57]. In this case, the diffusion is simulated as a random walk, and the volume of oil spilled is represented as Lagrangian elements that are driven by wind and surface currents [48]. GNOME may be adopted to predict the wind, currents, and other processes that could move and spread the oil spill over the water, as well as to study the oil trajectories that are affected by inaccuracies in actual and forecasted wind observations, including how the spilled oil is expected to change chemically and physically during the time it remains on the water surface [24].

The user can access to the GNOME website, he/she can insert and choose the information required to configure the scenario. The model setting consists in introducing the location, the starting time and the duration of the simulation but also the type of oil product and the data about wind and surface currents. Wind data may be added in different modalities, manually as a constant wind value or as a time-series, or by imported them from the National Weather Service (NWS) for the specified location. Ocean current data also can be imported into WebGNOME while the horizontal diffusion may be varied in respect to the default value. This platform provides the user with an effective and functional tool which is, in general, intuitive to be used and applicable for different scenarios and regions. The model is able to simulate different types of oil spills at different volumes and conditions such as instantaneous release from the ship, continuous-release, intentional tank discharge, and tank release. Output can be recorded in several formats, such as GIS-compatible movies and text files, which can be easily analysed by visualization and specific programs. The wind and current data can be easily converted into GNOME inputs, starting from operational ocean modelling system [43].

\section{CASE STUDY IN THE TYRRHENIAN SEA}

The oil spill accident that occurred in the Tyrrhenian Sea on the coast of Saint Tropez (France) on 7 October 2018, was chosen to test and evaluate the two proposed model applications. This accident occurred after the collision between a Cypriot container ship and a Tunisian vessel generating an oil discharge of 600 cubic meters in the Mediterranean Sea according to the estimate of public authorities [58]. From the available sources of data, it has been verified that main amount of oil spilled reached the French coast in 9 days. Fig. 2 shows the location of the collision accident in the Ligurian Sea. 


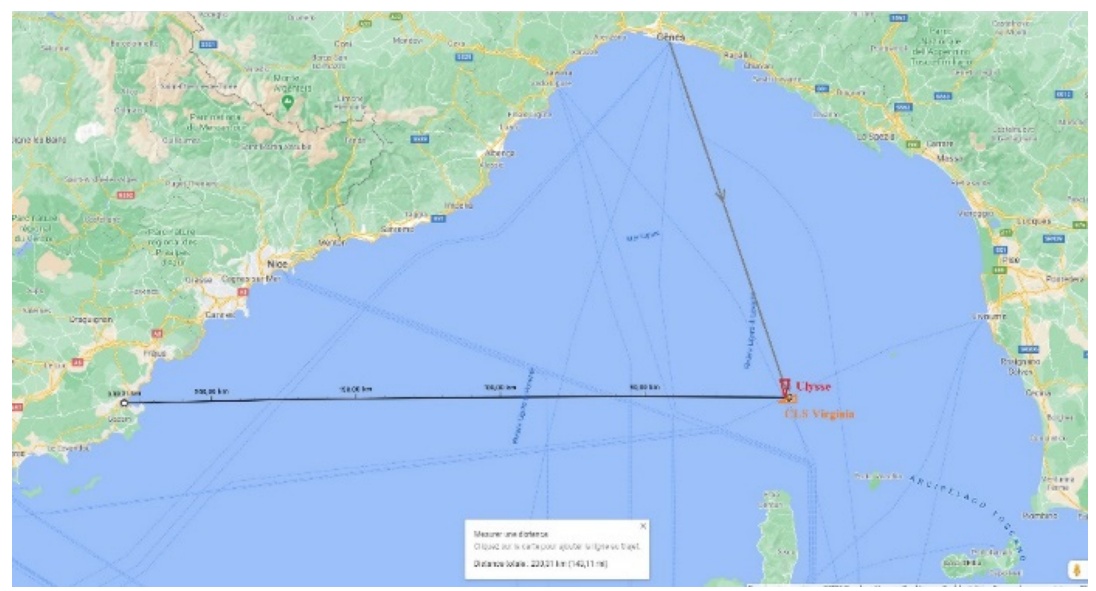

Figure 2: Location of collision accident in the Ligurian Sea.

\subsection{Weather conditions}

The main environmental information needed for a reliable prediction of oil slick movement is related to wind, water surface current which varied in time and space. The analysis of the meteorological condition in the selected area for the time horizon of 9 days from 7 October 2018 , shows that during the period of the incident (9 days), the wind blew from $13 \mathrm{~km} / \mathrm{h}$ to $46 \mathrm{~km} / \mathrm{h}$, mainly in the northeast direction, according to data coming from the Spanish Network of Measurements (REMRO Network) database. In addition, the surface current of the seawater was about $1 \mathrm{~m} / \mathrm{s}$ throughout the period. Fig. 3 shows the averages of the wind rose in the incident area during the selected period, and Table 1 shows the wind speed values during the selected period in the coastal area of Saint Tropez.

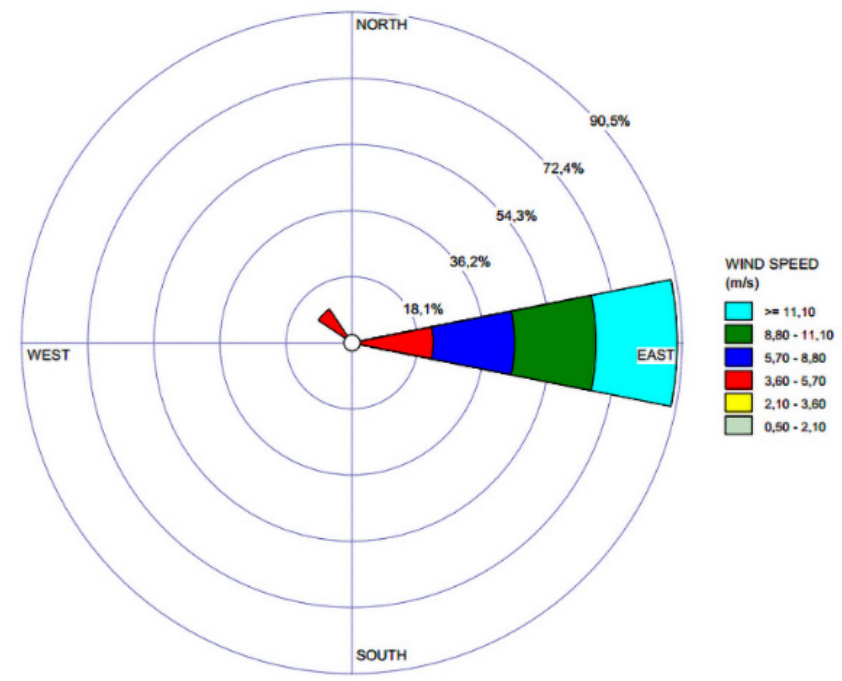

Figure 3: The averages of the wind rose in the incident area during the selected period. 
Table 1: Values of the wind speed during the 9 days after the accident.

\begin{tabular}{|c|c|}
\hline Date & Wind speed $(\mathbf{k m} / \mathbf{h})$ \\
\hline $\mathbf{7}$ October $\mathbf{2 0 1 8}$ & 13 \\
\hline $\mathbf{8}$ October $\mathbf{2 0 1 8}$ & 36 \\
\hline 9 October 2018 & 29 \\
\hline $\mathbf{1 0}$ October $\mathbf{2 0 1 8}$ & 44 \\
\hline $\mathbf{1 1}$ October $\mathbf{2 0 1 8}$ & 29 \\
\hline $\mathbf{1 2}$ October $\mathbf{2 0 1 8}$ & 14 \\
\hline $\mathbf{1 3}$ October $\mathbf{2 0 1 8}$ & 17 \\
\hline $\mathbf{1 4}$ October 2018 & 34 \\
\hline $\mathbf{1 5}$ October 2018 & 46 \\
\hline
\end{tabular}

4 APPLICATION OF THE PROPOSED MODELS

During the nine days following the collision accident, the oil residues reached the coastal area where more than $16 \mathrm{~km}$ of French shoreline were affected, with almost 50 beaches damaged in 11 French municipalities [59]. The oil spill recovery operations were delayed due to the adverse meteorological conditions during that period in which the high wind speed reached values over $29 \mathrm{~km} / \mathrm{h}$ most of the time.

The results of the oil spill trajectory simulation are presented in the following two figures. Fig. 4 shows the application of the proposed 2D Lagrangian model. The simulated propagation of the oil slick, in the different days, is integrated into a map generated by a geographic information system (GIS). Fig. 5 shows the results the GNOME application, highlighting for each day of the simulation, the directional movements of the slick until it reached the French coast.

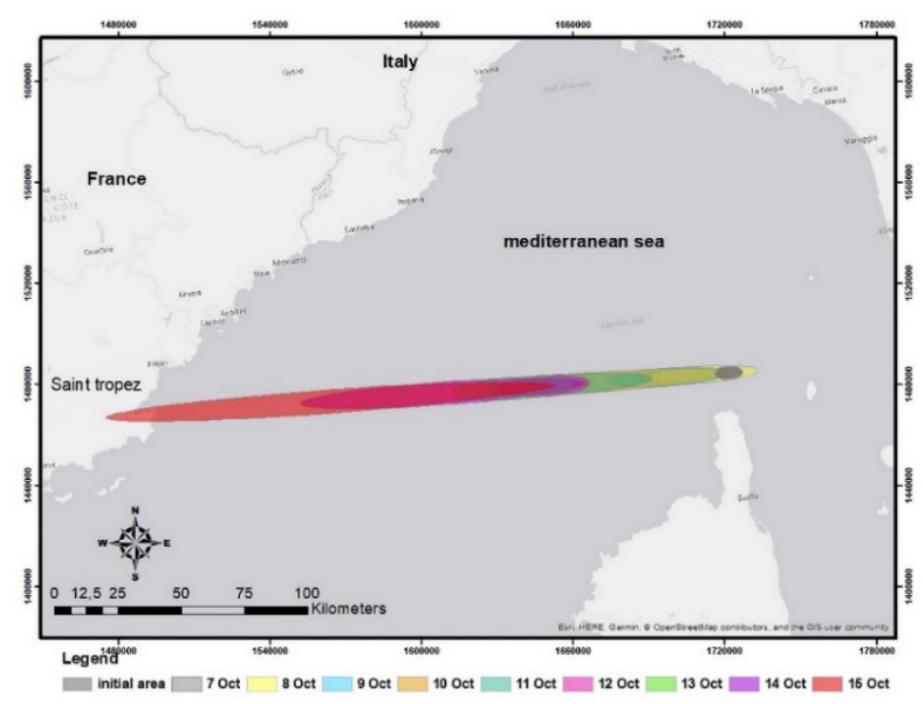

Figure 4: The 2D model application for the proposed case study. 

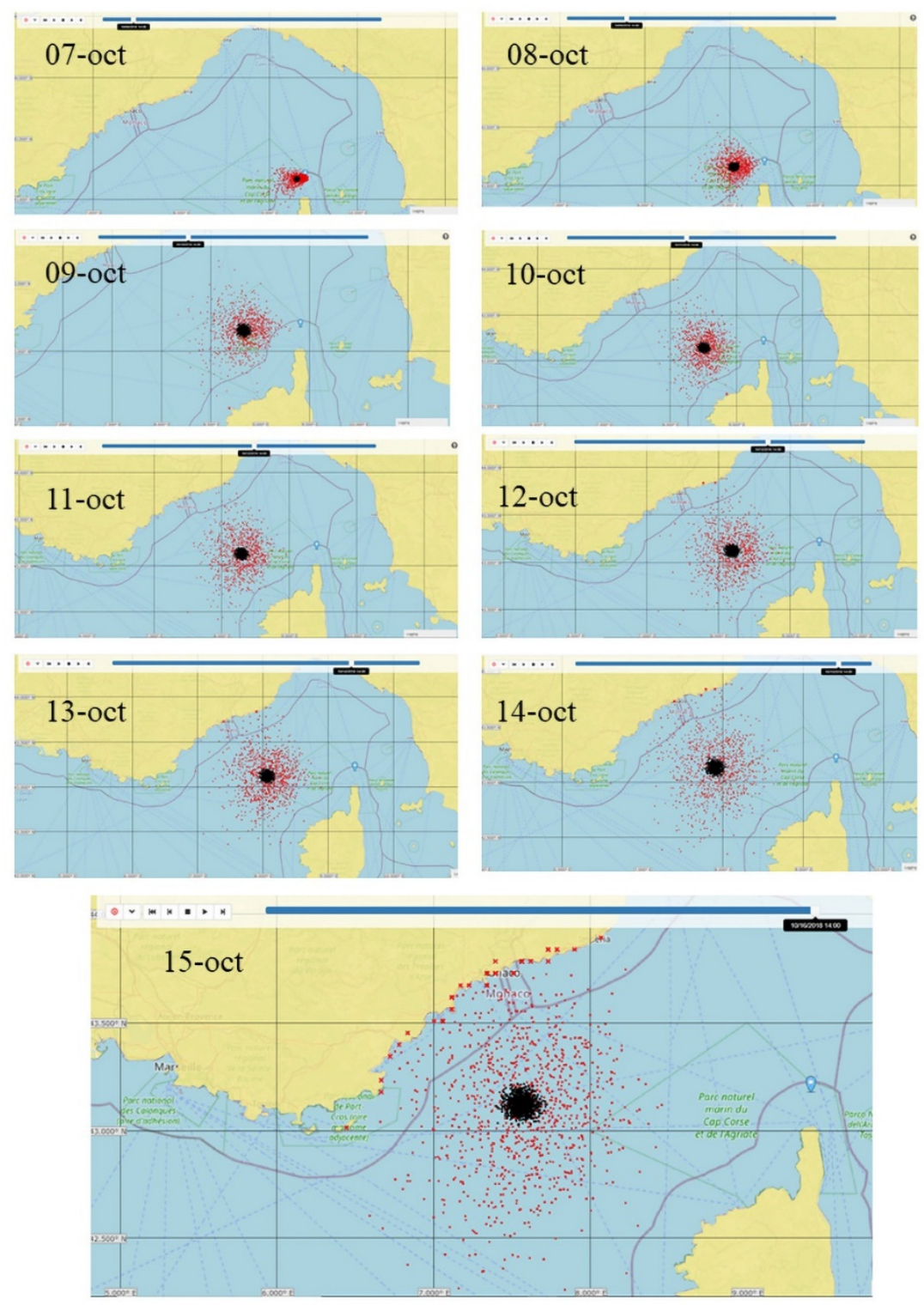

Figure 5: The GNOME model application for the proposed case study.

According to the proposed 2D Lagrangian model, the simulation of the oil slick trajectory during the study period of 7-15 October 2018 (9 days) consisted in a set of consecutive elliptical shapes as appears in the Fig. 4. However, the reliability of the proposed approach to predict the oil spill trajectories on the sea surface, as reported in [46], has been positively verified with good accuracy. The actual data and simulated case study confirmed that the oil spill reached the French coast in 9 days. Simulation results obtained by the 2D model show that the oil slick covered a distance of about $6 \mathrm{~km}$ and it was directed to the southwest in the 
first 24 hours. During the period between 8 and 9 October, the oil slick moved a distance of about $15 \mathrm{~km}$. During the fourth day, when the wind speed was very high, with a value of about $44 \mathrm{~km} / \mathrm{h}$, the oil slick travelled a distance of about $50 \mathrm{~km}$. In the three days, from October 11 to 13, the oil slick travelled a distance of about $87 \mathrm{~km}$. On the last two days of the study, from 14 to 15 October, the oil slick moved in the direction of Saint Tropez, covering a distance of more than $160 \mathrm{~km}$. Thus, the results obtained by the proposed 2D model appear approximately consistent with the actual trajectory generated by the slick to reach the coast of Saint Tropez for about $230 \mathrm{~km}$ in 9 days after the accident.

The simulation results, obtained by the GNOME model (Fig. 5), presents the simulated distribution of the oil spill for each day of the time horizon. The application results, based on the input data presented in the paragraph 3 , show that the first small oil spots reached some French beaches among the 7th and 8th day after the collision incident depending on the wind direction. In the 9th day several beaches have been affected by oil spots. This emphasizes that the discrepancy between the actual observations and the modelled results is minimal and that the trajectory obtained by the GNOME model approximately correspond to the actual path and timing achieved by the oil spill in the real case study in the Ligurian Sea.

\section{CONCLUSION}

The purpose and capability of oil slick drift models range from a simple trajectory tracking by a $2 \mathrm{D}$ model to a $3 \mathrm{D}$ transport model able to predict surface oil distributions in the water column. In addition, the 3D more complex models can quantify biological responses and environmental impacts. The simulation results, obtained by the two models and the scenarios obtained for the collision accident, demonstrated that the proposed prediction models are accurate in space and time. The proposed 2D model predicts with reliability, quickness and accuracy, the movements and trajectories of oil slicks at the sea surface. This approach displays the movements of the oil slick considering the translation of the elliptical shape along the wind direction and according to its speed. On the contrary, the GNOME tool based on the 3D model provides quite different results in terms of precision of the oil spots positions. The possibility to evaluate the chemical and physical processes which involved the released products in the deep-sea water provides a more detailed prediction of the oil slick displacement. In this approach, the diffusion of the pollution is exhibited by the area of the spill sprayed which provides a more realistic representation of the event evolution. This reflects the effectiveness of the model, given adequate and precise environmental information of the impact area. However, the 2D models may run quickly inasmuch as they do not integrate the results on the vertical dimension. They are also based on the assumptions and approximations about climatic and oceanographic data that are conditioned and limited by the existence of a domain of validity of the models (hydrostatic pressure, negligible vertical velocity). The 3D models - such as GNOME - take into account the weathering of the spilled oil by defining four natural processes in the model: evaporation, natural dispersion, sedimentation, and emulsification. The integration of those processes assures the quantification of the biological responses, and therefore it makes the system robust to reflect the effectiveness of this model.

However, the 2D models used to predict oil slick drift calculated only the vertically integrated current, forced by the tide and winds. To estimate the surface drift speed of the slick, a percentage of the surface wind speed between $1 \%$ and $5 \%(3.5 \%$ in our case) was added to the calculated current speed. This type of model remains suitable to trace dissolved product in an area with predominance of tidal currents and without vertical stratification. However, its use may be inappropriate in highly stratified regions, where the threedimensional structure of the current is important. The inability to predict near-surface current 
gradients is also a real drawback to simulate dispersed oil drift. Although this type of 2D model is not conservative (vertical currents are not calculated), and it cannot take into account possible baroclinic effects (including density), it predicts the behaviour of oil in the surface layer. This type of model is commonly used for operational applications.

The majority of the complete algorithms developed to describe the behaviour of hydrocarbons at sea work with the support of fully 3D models that provide the essential hydrodynamic data. This is the case of the Gnome model for example. These models calculate temperature and salinity in the three dimensions and they are able to reproduce possible thermal or haline stratifications.

\section{ACKNOWLEDGEMENTS}

This research is supported by the Project OMD, Observatoire des Marchandises Dangereuses (Observatory for dangerous goods) co-financed by the European Regional Development Fund in the framework of the Interreg Italy-France Maritime Programme 2014-2020, available at http://interreg-maritime.eu/web/OMD/progetto (Last access April 2021).

\section{REFERENCES}

[1] Farrington, J.W., Oil pollution in the marine environment II: Fates and effects of oil spills. Environment, 56(4), pp. 16-31, 2014.

[2] Farrington, J.W., Oil pollution in the marine environment I: Inputs, big spills, small spills, and dribbles. Environ. Sci. Policy Sustain. Dev., 55(6), pp. 3-13, 2013.

[3] Kingston, P.F., Long-term environmental impact of oil spills. Spill Sci. Technol. Bull., 7(3-4), pp. 53-61, 2002. DOI: 10.1016/S1353-2561(02)00051-8.

[4] Dagdougui, H., Sacile, R., Bersani, C. \& Ouammi, A., Hydrogen Infrastructure for Energy Applications: Production, Storage, Distribution and Safety, Academic Press, pp. 1-156, 2018. https://www.sciencedirect.com/book/9780128120361/hydrogeninfrastructure-for-energy-applications.

[5] Bersani, C., \& Roncoli, C., Real-time risk definition in the transport of dangerous goods by road. Proceedings of the 7th International Conference on System of Systems Engineering (SoSE 2012), pp. 131-136, 2012. DOI: 10.1109/SYSoSE.2012.6384192.

[6] Benza, M. et al., Intelligent transport systems (its) applications on dangerous good transport on road in Italy. 2012 7th International Conference on System of Systems Engineering (SoSE), IEEE, pp. 223-228, 2012.

[7] Bersani, C., Papa, F., Sacile, R., Sallak, M. \& Terribile, S., Towards dynamic exposure-based schedule for hazardous material trains. J. Rail Transp. Plan. Manag., 6(2), pp. 116-127, 2016.

[8] Witchaya, R. et al., Formulation of crude oil spill dispersants based on the HLD concept and using a lipopeptide biosurfactant. J. Hazard. Mater., 334, pp. 168-177, 2017.

[9] Al-Majed, A., Adebayo, A. \& Hossain, M., A sustainable approach to controlling oil spills. J. Environ. Manage., 2012.

[10] Vega, F., Emma, A., Covelo, F., Reigosa, J.M. \& Luisa Andrade, M., Degradation of fuel oil in salt marsh soils affected by the Prestige oil spill. J. Hazard. Mater., 166(23), pp. 1020-1029, 2009.

[11] Soussi, A., Bersani, C. \& Sacile, R., Environmental impacts of oil spills and response technologies. Advances in Environmental Research, vol. 80, 80th edn, ed. Justin A. Daniels, Nova Science Publishers, 2021.

[12] Jafarinejad, S., Environmental impacts of the petroleum industry. Protection Options, and Regulations, 2017. 
[13] Dave, D. \& Ghaly, A.E., Remediation technologies for marine oil spills: A critical review and comparative analysis. Am. J. Environ. Sci., 7(5), pp. 424-440, 2011. DOI: 10.3844/ajessp.2011.424.440.

[14] Guo, W., Development of a statistical oil spill model for risk assessment. Environ. Pollut., 230, pp. 945-953, 2017. DOI: 10.1016/j.envpol.2017.07.051.

[15] Soussi, A. et al., Coastal risk modelling for oil spill in the Mediterranean Sea. Adv. Sci. Technol. Eng. Syst., 5(4), pp. 273-286, 2020. DOI: 10.25046/aj050434.

[16] Goldman, R., Biton, E., Brokovich, E., Kark, S., \& Levin, N., Oil spill contamination probability in the southeastern Levantine basin. Mar. Pollut. Bull., 91(1), pp. 347-356, 2015. DOI:10.1016/j.marpolbul.2014.10.050.

[17] Melaku Canu, D. et al., Assessment of oil slick hazard and risk at vulnerable coastal sites. Mar. Pollut. Bull., 94(1-2), pp. 84-95, 2015.

[18] Azevedo, A., Oliveira, A., Fortunato, A.B., Zhang, J. \& Baptista, A.M., A cross-scale numerical modeling system for management support of oil spill accidents. Mar. Pollut. Bull., 80(1-2), pp. 132-147, 2014.

[19] Romero, A.F., Abessa, D.M.S., Fontes, R.F.C. \& Silva, G.H., Integrated assessment for establishing an oil environmental vulnerability map: Case study for the Santos Basin region, Brazil. Mar. Pollut. Bull., 74(1), pp. 156-164, 2013.

[20] De Dominicis, M., Pinardi, N., Zodiatis, G. \& Lardner, R., MEDSLIK-II, a Lagrangian marine surface oil spill model for short-term forecasting-Part 1: Theory. Geosci. Model Dev., 6(6), pp. 1851-1869, 2013. DOI: 10.5194/gmd-6-1851-2013.

[21] Paiva, P.M., Lugon Junior, J., Barreto, A.N., Silva, J.A.F. \& Silva Neto, A.J., Comparing $3 \mathrm{~d}$ and $2 \mathrm{~d}$ computational modeling of an oil well blowout using MOHID platform - A case study in the Campos Basin. Sci. Total Environ., 595, pp. 633-641, 2017. DOI:10.1016/j.scitotenv.2017.04.007.

[22] Spaulding, M.L., State of the art review and future directions in oil spill modelling. Mar. Pollut. Bull., 115(1-2), pp. 7-19, 2017.

[23] Amir-Heidari, P. \& Raie, M., A new stochastic oil spill risk assessment model for Persian Gulf: Development, application and evaluation. Mar. Pollut. Bull., 145, pp. 357-369, 2019. DOI:10.1016/j.marpolbul.2019.05.022.

[24] Zelenke, B., O'Connor, C., Barker, C. \& Beegle-Krause, C.J., General NOAA Operational Modeling Environment (GNOME), Technical Documentation. U.S. Dept. Commer. NOAA Tech. Memo. NOS OR\&R 40, p. 105, 2012.

[25] Beegle-Krause, C.J., General NOAA oil modeling environment (GNOME): A new spill trajectory model. Int. Oil Spill Conf., 2, pp. 865-871, 2001.

[26] Lehr, W., Jones, R., Evans, M., Simecek-Beatty, D. \& Overstreet, R., Revisions of the ADIOS oil spill model. Environ. Model. Softw., 17(2), pp. 189-197, 2002.

DOI: 10.1016/s1364-8152(01)00064-0.

[27] Park, S.H., Jung, H.S. \& Lee, M.J., Oil spill mapping from Kompsat-2 high-resolution image using directional median filtering and artificial neural network. Remote Sens., 12(2), 2020. DOI: 10.3390/rs12020253.

[28] Toz, A. C. \& Buber, M., Performance evaluation of oil spill software systems in early fate and trajectory of oil spill: Comparison analysis of OILMAP and PISCES 2 in Mersin bay spill. Environ. Monit. Assess., 190(9), 2018. DOI: 10.1007/s10661-0186872-3.

[29] Spaulding, M.L., Kolluru, V.S., Anderson, E., \& Howlett, E., Application of threedimensional oil spill model (WOSM/OILMAP) to Hindcast the Braer spill. Spill Sci. Technol. Bull., 1(1), pp. 23-35, 1994. 
[30] Barreto, F.T.C. et al., Comparison of the coupled model for oil spill prediction (CMOP) and the oil spill contingency and response model (OSCAR) during the DeepSpill field experiment. Ocean Coast. Manag., 204, 2021.

DOI: 10.1016/j.ocecoaman.2021.105552.

[31] Reed, M, Ekrol, N., Rye, H. \& Turner, L., Oil spill contingency and response (OSCAR) analysis in support of environmental impact assessment offshore Namibia. Spill Sci. Technol. Bull., 5(1), pp. 29-38, 1999.

[32] De Pablo, H., Sobrinho, J., Garcia, M., Campuzano, F., Juliano, M., \& Neves, R., Validation of the 3D-MOHID hydrodynamic model for the Tagus coastal area. Water, 11(8), 2019. DOI: 10.3390/w11081713.

[33] Berry, A., Dabrowski, T., \& Lyons, K., The oil spill model OILTRANS and its application to the Celtic Sea. Mar. Pollut. Bull., 64(11), pp. 2489-2501, 2012. DOI: 10.1016/j.marpolbul.2012.07.036.

[34] De Dominicis, M., Pinardi, N., Zodiatis, G., \& Archetti, R., MEDSLIK-II, a Lagrangian marine surface oil spill model for short-term forecasting - Part 2: Numerical simulations and validations. Geosci. Model Dev., 6(6), pp. 1871-1888, 2013. DOI: $10.5194 /$ gmd-6-1871-2013.

[35] Periáñez, R., A Lagrangian oil spill transport model for the Red Sea. Ocean Eng., 217, p. 107953, 2020. DOI: 10.1016/j.oceaneng.2020.107953.

[36] Qiao, F. et al., Modelling oil trajectories and potentially contaminated areas from the Sanchi oil spill. Sci. Total Environ., 685, pp. 856-866, 2019.

DOI: $10.1016 /$ j.scitotenv.2019.06.255.

[37] Liu, X. et al., Modelling of oil spill trajectory for 2011 Penglai 19-3 coastal drilling field, China. Appl. Math. Model., 39(18), pp. 5331-5340, 2015.

DOI: $10.1016 /$ j.apm.2014.10.063.

[38] Afenyo, M., Khan, F., Veitch, B. \& Yang, M., Modeling oil weathering and transport in sea ice. Mar. Pollut. Bull., 107(1), pp. 206-215, 2016.

DOI: 10.1016/j.marpolbul.2016.03.070.

[39] Lonin, S.A., Lagrangian model for oil spill diffusion at sea. Spill Sci. Technol. Bull., 5(5-6), pp. 331-336, 1999. DOI: 10.1016/S1353-2561(99)00078-X.

[40] Guo, W.J. \& Wang, Y.X., A numerical oil spill model based on a hybrid method. Mar. Pollut. Bull., 58(5), pp. 726-734, 2009.

[41] El-Fadel, M., Abdallah, R. \& Rachid, G., A modeling approach toward oil spill management along the Eastern Mediterranean. J. Environ. Manage., 113(2012), pp. 93-102, 2012. DOI:10.1016/j.jenvman.2012.07.035.

[42] Wang, S.D., Shen, Y.M., Guo, Y.K. \& Tang, J., Three-dimensional numerical simulation for transport of oil spills in seas. Ocean Eng., 35(5-6), pp. 503-510, 2008. DOI:10.1016/j.oceaneng.2007.12.001.

[43] Marta-Almeida, M. et al., Efficient tools for marine operational forecast and oil spill tracking. Mar. Pollut. Bull., 71(1-2), pp. 139-151, 2013.

DOI:10.1016/j.marpolbul.2013.03.022.

[44] Lehr, W.J., Review of modeling procedures for oil spill weathering behaviour. Adv. Ecol. Sci., 9(5), pp. 51-90, 2001.

[45] Mishra, A.K. \& Kumar, G.S., Weathering of oil spill: Modeling and analysis. Aquat. Procedia, 4, pp. 435-442, 2015.

[46] Soussi, A. et al., An oil spill trajectory model: Validation in the Mediterranean Sea. 2019 International Symposium on Systems Engineering (ISSE), IEEE, pp. 1-6, 2019. DOI: 10.1109/ISSE46696.2019.8984542. 
[47] Nordam, T., Nepstad, R., Litzler, E. \& Röhrs, J., On the use of random walk schemes in oil spill modelling. Mar. Pollut. Bull., 146, pp. 631-638, 2019.

[48] Xu, Q., Li, X., Wei, Y., Tang, Z., Cheng, Y., \& Pichel, W.G., Satellite observations and modeling of oil spill trajectories in the Bohai Sea. Mar. Pollut. Bull., 71(1-2), pp. 107-116, 2013. DOI: 10.1016/j.marpolbul.2013.03.028.

[49] French-McCay, D.P., Oil spill impact modeling: Development and validation. Environ. Toxicol. Chem., 23(10), pp. 2441-2456, 2004.

[50] Nixon, Z. \& Michel, J., Predictive modeling of subsurface shoreline oil encounter probability from the Exxon Valdez oil spill in Prince William Sound, Alaska. Environ. Sci. Technol., 49(7), pp. 4354-4361, 2015. DOI: 10.1021/es502579u.

[51] Xu, H.L., Chen, J.N., Wang, S.D. \& Liu, Y., Oil spill forecast model based on uncertainty analysis: A case study of Dalian oil spill. Ocean Eng., 54, pp. 206-212, 2012. DOI: 10.1016/j.oceaneng.2012.07.019.

[52] Periáñez, R. \& Caravaca, F., A set of rapid-response models for pollutant dispersion assessments in southern Spain coastal waters. Mar. Pollut. Bull., 60(9), pp. 1412-1422, 2010. DOI: 10.1016/j.marpolbul.2010.05.016.

[53] Fay, J., Physical processes in the spread of oil on a water surface. Proceeding Jt. Conf. Prev. Control Oil Spills, 1971.

[54] Berry, A., Development of OILTRANS Model Code. 2011.

[55] Al-Rabeh, A.H., Cekirge, H.M. \& Gunay, N., A stochastic simulation model of oil spill fate and transport. Appl. Math. Model., 13(6), pp. 322-329, 1989. DOI: 10.1016/0307-904X(89)90134-0.

[56] NOAA Office of Response and Restoration's Emergency Response Division, General NOAA Operational Modelling Environment (GNOME). https://response.restoration.noaa.gov/gnome_manual.

[57] Balogun, A.L., Yekeen, S.T., Pradhan, B. \& Wan Yusof, K.B., Oil spill trajectory modelling and environmental vulnerability mapping using GNOME model and GIS. Environ. Pollut., 268, p. 115812, 2021. DOI: 10.1016/j.envpol.2020.115812.

[58] Vazquez, C., Collision au large de la Corse: les deux navires toujours encastrés. https://www.lefigaro.fr/sciences/2018/10/08/01008-20181008ARTFIG00174collision-de-deux-navires-au-large-de-la-corse-des-operations-de-depollution-encours.php. Accessed on: Apr. 2021.

[59] Le nouvelliste, Neuf jours après la collision qui s'est déroulée au large de la Corse entre un porte-conteneurs chypriote et un bateau tunisien, des plaques d'hydrocarbure et des boulettes noires de mazout se déplacent jusqu'aux côtes de Saint-Tropez, 2018. https://www.lenouvelliste.ch/articles/monde/france-du-petrole-sur-des-plages-desaint-tropez-suite-a-une-collision-de-bateaux-792528. Accessed on: Apr. 2021. 